\title{
Phosphorylation of spliceosomal protein SAP 155 coupled with splicing catalysis
}

\section{Changyu Wang, ${ }^{1,3,4}$ Katrin Chua, ${ }^{1,3}$ Wolfgang Seghezzi, ${ }^{2,3}$ Emma Lees, $^{2}$ Or Gozani, ${ }^{1}$ and Robin Reed ${ }^{1,5}$}

\begin{abstract}
${ }^{1}$ Department of Cell Biology, Harvard Medical School, Boston, M assachusetts 02115 USA; ${ }^{2}$ DN AX Research Institute, Palo Alto, California 94034 USA

The U2 snRNP component SAP 155 contacts pre-mRNA on both sides of the branch site early in spliceosome assembly and is therefore positioned near or at the spliceosome catal ytic center. We have isol ated a cDNA encoding human SAP 155 and identified its highly related Saccharomyces cerevisiae homolog ( $50 \%$ identity). The carboxy-terminal two-thirds of SAP 155 shows the highest conservation and is remarkably similar to the regulatory subunit A of the phosphatase PP2A. Significantly, SAP 155 is phosphorylated concomitant with or just after catalytic step one, making this the first example of a protein modification tightly regulated with splicing ca talysis.
\end{abstract}

Received N ovember 14, 1997; revised version accepted M arch 11, 1998.

Spliceosomal complexes assemble on pre-mRNA in the order E, A, B, and C, with the catalytic steps taking place in the C complex (for review, see Kramer 1996). Step 1 is a nucleophilic attack on the $5^{\prime}$ splice site (ss) by the branch-site adenosine, which is bulged from a duplex between U 2 snRN A and the branchpoint sequence (BPS). This duplex is established in the A complex concomitant with binding of six U2 snRNP proteins [spliceosomeassociated proteins (SAPs) 49, 61, 62, 114, 145, and 155] near the BPS. These proteins are components of two multiprotein complexes, SF3a and SF3b, which are required for A complex assembly (for review, see Kramer 1996; Reed 1996). SF3a consists of three subunits, SF3a ${ }^{60}, \mathrm{SF} 3 \mathrm{a}^{66}, \mathrm{SF} 3 \mathrm{a}^{120}$ (corresponding to SAPs 61,62 , and 114, respectively), and SF3b consists of at least four subunits, SF $3 b^{50}, \mathrm{SF} 3 b^{130}, \mathrm{SF} 3 b^{145}$, and $\mathrm{SF}^{13 b^{155}}$ (SAPs $49,130,145$, and 155, respectively; we will use the SAP nomenclature). CDNAs encoding all of the SF3a and two of the SF3b subunits (SAPs 145 and 49) have been isolated and Saccharomyces cerevisiae homologs identified (Kramer 1996; Reed 1996). The SF3a subunits are all essential in yeast and required for A complex assembly. ySAP 145 , originally identified by its similarity to hu-

[Key Words: U2 snRN P; SAP 155 phosphorylation; spliceosome; splicing] ${ }^{3}$ These authors contributed equally to this work.

4Present address: Center for Cancer Research, Massachusetts Institute of Technology, Cambridge, Massachusetts 02139 USA.

${ }^{5}$ Corresponding author.

E-MAIL reed@warren.med.harvard.edu; FAX (617) 432-3091. man SAP 145 (Gozani et al. 1996), corresponds to the CU Sl gene, isolated as a suppressor of a U 2 snRN A mutation (Wells et al. 1996). CU S1 is essential in yeast and is required for A complex assembly (Wells et al. 1996).

In the mammalian A complex, the SF3a/b subunits cross-link to a 25-nucleotide region in the premRNA located immediately upstream of the BPS (Gozani et al. 1996). These RNA-protein interactions are thought to function in part to anchor U 2 snRN P to the BPS (Gozani et al. 1996). SAP 155 cross-links to pre-mRN A on both sides of the branch site (O. Gozani, J. Potashkin, and R. Reed, in prep.) and is thus strategically positioned over the branch-site adenosine before this residue undergoes nucleophilic attack on the $5^{\prime}$ ss. This location and timing of the SAP 155-pre-mRN A interactions suggest that SAP 155 is a critical component of the spliceosome active site. Here we report the isolation of a cDN A encoding SAP 155 and find that it is the most highly conserved SF3 component. We also show that SAP 155 is phosphorylated concomitant with splicing catalysis. The functional importance of SAP 155 phosphorylation for splicing is indicated by the observations that phosphorylation is detected only in functional spliceosomes, is regul ated with catal ysis and occurs general ly with different pre-mRN As, and that phosphorylated SAP 155 contacts both sides of the branch site during catalysis.

\section{Results}

Isolation of SAP 155 CDNA

To isolate a human SAP 155 cDNA, spliceosomal complex $A$ was purified in large scale and fractionated by SDS-PAGE, and peptide sequences were obtained from tryptic digestion products of SAP 155 (Bennett and Reed 1993). One of the peptide sequences matched an EST in GenBank, and this EST was used to screen libraries to obtain the SAP 155 CDNA. This CDNA is predicted to encode a 1304-amino-acid protein with a mol ecular mass of $146 \mathrm{kD}$ (Fig. 1A). SAP 155 is most similar to the regulatory subunit A of the phosphatase PP2A (Ruediger et al. 1994). PP2A-A is organized in 15 nonidentical repeats, 38-43 amino acids in length; the consensus is shown bel ow the SAP 155 sequence (Ruediger et al. 1994; Fig. $1 A)$. These repeats are thought to fold PP2A-A into a rod-like structure that interacts directly with the regulatory B and catalytic C subunits (Ruediger et al. 1994). The carboxy-terminal two-thirds of SAP 155 can be aligned into 22 PP2A-like repeats. SAP 155 and PP2A-A contain few exact matches at many positions in the PP2A-A consensus; rather, the main characteristic of these repeats is a specific distribution of hydrophobic and charged residues. In PP2A-A, the amino acids at positions 5-7 in the consensus are LLP (Fig. 1A). Only two repeats have this exact sequence; the others are composed of related residues (e.g., IIP, LVP). Similarly, in SAP 155, there are two LLPs at positions 5-7 of the repeats and several related sequences. Like PP2A-A, SAP 155 is enriched in serines or threonines at position 1 , 

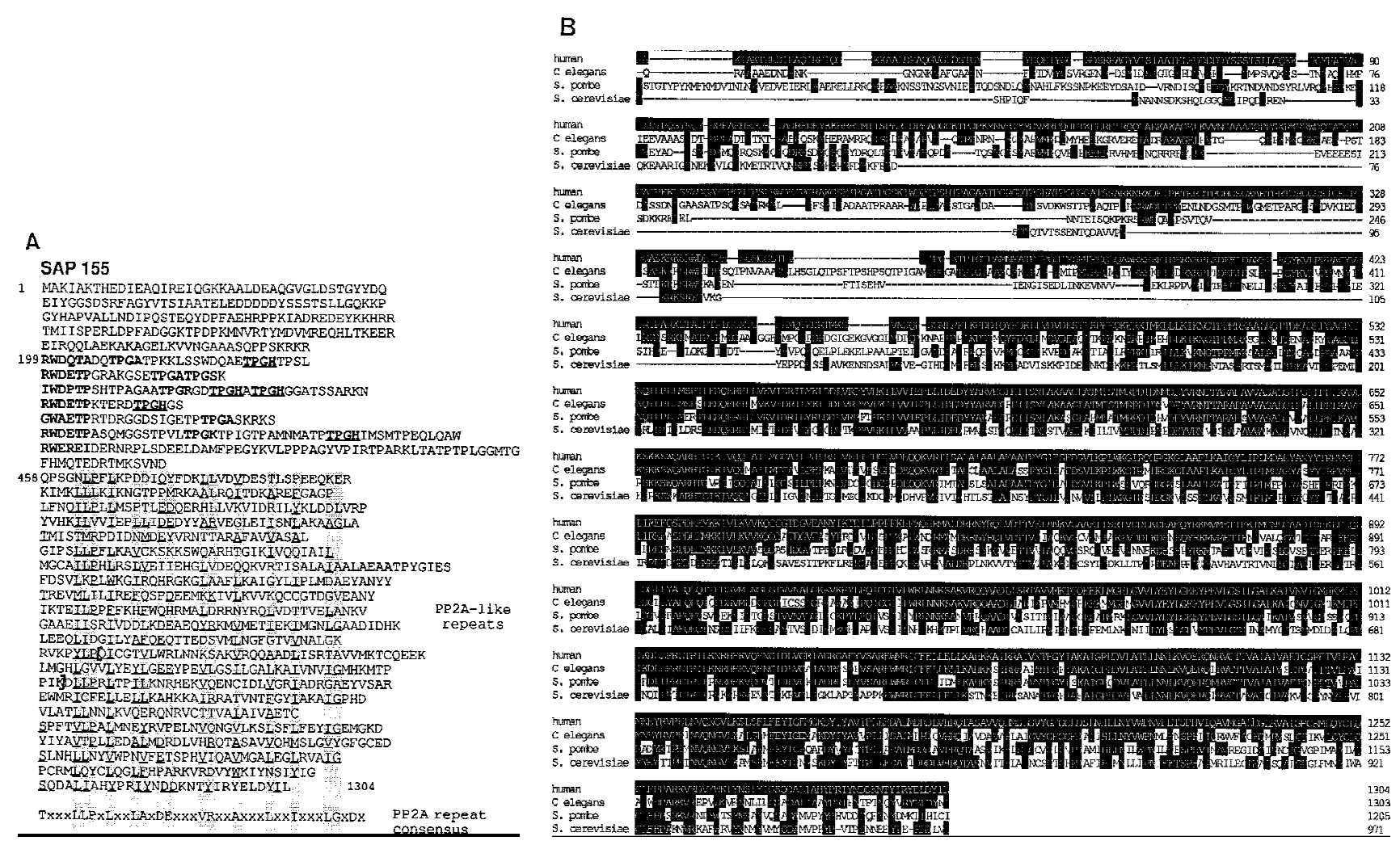

Figure 1. (A) The amino acid sequence predicted from the human SAP 155 CDNA sequence. The RWDETP repeats at the amino terminus are aligned for convenience. These repeats and the TPGX repeats are indicated in boldface type, and the TPGH repeats are al so underlined. The PP2A-like repeats are al igned according to the consensus for PP2A. This consensus is shown bel ow the SAP 155 sequence. The underlined amino acids indicate those that match the consensus or are similar in type (hydrophobic or charged) to the consensus residue. The brackets indicate the 82 -amino-acid region that is missing from the $\triangle$ SAP 155 cDNA (see Materials and M ethods). (B) SAP 155 homologs are shown aligned with human SAP 155. Identities are indicated in white on black. ceSAP 155, spSAP 155, and scSAP 155 correspond to the C. elegans, S. pombe, and S. cerevisiae proteins, respectively.

pairs of acidic residues at positions 15 and 16, hydrophobic residues at positions 24 and 31, and glycines at position 36. The si milar organization of SAP 155 and PP2A-A suggests that these proteins fold into a similar structure and that the PP2A-A repeats in SAP 155 play a role in as yet unidentified protein-protein interactions.

The amino terminus of SAP 155 is hydrophilic and contains two types of repeats (Fig. 1A). There are three perfect and several degenerate repeats of the sequence RWDETP. There are also five repeats of the sequence TPGH and several derivatives in which the last amino acid is either basic $(K, R)$ or small $(A, S)$. These repeats closely resemble phosphorylation sites for the C $\mathrm{dk}$ serine-threonine kinases (S/T-P-X-R/K) ( $M$ oreno and N urse 1990).

\section{SAP 155 is the most highly conserved SF3 subunit}

Probable S. cerevisiae, Schizosaccharomyces pombe, and Caenorhabditis elegans homologs of SAP 155 were identified in GenBank (Fig. 1B). Both the size and sequence of these homologs are strikingly conserved: SCSAP 155 is 50\% identical to human SAP 155; ceSAP 155 and spSAP 155 are $\sim 6 \%$ and $56 \%$ identical to SAP 155 , respectively. The highest conservation lies in the carboxy-terminal two-thirds of the protein, which con- tains the PP2A-like repeats. Over this region, ceSAP 155 and spSAP 155 are $86 \%$ and $75 \%$ identical to SAP 155 , respectively. Virtually the entire SCSAP 155 protein consists of these repeats, and they are $55 \%$ identical to SAP 155.

SAP 155 is phosphorylated late in the splicing pathway

To investigate the role of SAP 155 in splicing, we raised antibodies to two peptides. These antibodies specifically immunoprecipitate in vitro-translated SAP 155, detect SAP 155 on Western blots of the A complex or nuclear extract (NE), and immunoprecipitate a small fraction of U2 snRN P from NE (see below; data not shown). The antibodies do not inhibit either A complex assembly or the splicing reaction, possibly because the epitope is mostly masked in extracts (data not shown).

The antibody was used for Western anal ysis of spliceosomal complexes at different steps of the splicing pathway. Initially, complexes were assembled on $\triangle A G$ premRNA, which contains a GG $\rightarrow$ AG substitution at the 3' ss (Gozani et al. 1994) (Fig. 2A). This mutation does not affect assembly of the $A, B$, and $C$ complexes but blocks step 2 of splicing. After a long incubation under splicing conditions, the $\mathrm{C}$ complex containing high lev- 


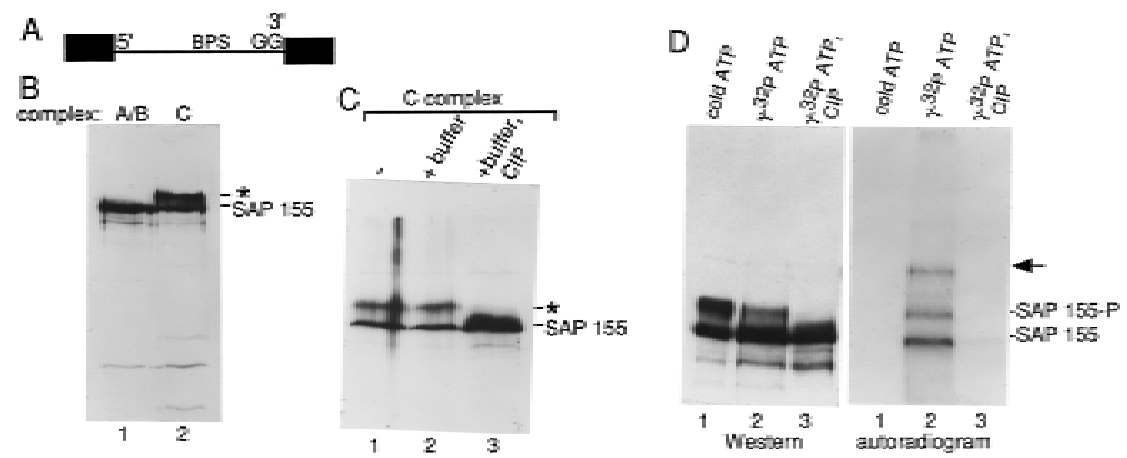

Figure 2. SAP 155 is phosphorylated in the $C$ complex assembled on $\triangle A G$ premRNA. (A) Schematic of $\triangle A G$ AdM L pre-mRN A; (B) Western bl ot of A/B (lane 1 ) and C (lane 2) complexes probed with SAP 155 antibodies; (C) Western blot of the C complex al one (lane 1), incubated in buffer (lane 2), or incubated in buffer and phosphatase (CIP) (lane 3). The asterisk indicates the novel band detected in the $C$ complex. (D) The C complex was assembled under standard splicing conditions (lane 1 ) or in a reaction containing $\left[\gamma^{3}{ }^{32} \mathrm{P}\right]$ ATP (lane 2$)$. An al iquot of the radiolabeled $\mathrm{C}$ complex was treated with CIP (lane 3). The autoradi ograph (right) and Western bl ot (left) probed with SAP 155 antibodies are shown. The arrow indicates the 200-kD protein that is phosphorylated and also weakly detected by the antisera.

els of step 1 products accumulates on $\triangle \mathrm{AG}$ pre-mRNA (Gozani et al. 1996). Spliceosomal complexes A/B or C were isolated and used for Western analysis. SAP 155 was detected in the A/B complex (Fig. 2B, lane 1). Surprisingly, another major band was detected in the $C$ complex (asterisk; Fig. 2B, lane 2). As SAP 155 contains multiple potential phosphorylation sites (see Fig. 1A), we tested whether this additional band is a phosphorylated form of SAP 155. Incubation of affinity-purified C complex with calf intestinal alkaline phosphatase (CIP) results in the loss of the slower-mobility band and an increase in the levels of the SAP 155 band (Fig. 2C). Addition of the phosphatase inhibitor vanadate eliminates the effect of CIP treatment (data not shown). These data indicate that SAP 155 is modified by phosphorylation.

To obtain further evidence that the CIP-sensitive form of SAP 155 is phosphorylated, the $C$ complex was assembled using [ $\gamma^{-32}$ PJATP fractionated by SDS-PAGE and immobilized on a membrane. ${ }^{32} \mathrm{P}$-Labeled proteins were detected by autoradiography and compared with Western analysis of the same blot using SAP 155 antisera (Fig. 2D). As shown in lane 2, three major high-molecular- mass bands were detected in the $C$ complex on the autoradiograph (right). Significantly, two of these comigrate with the major bands detected by the SAP 155 anti body (Fig. 2D, lane 2, cf. Western and autoradi ograph). A 200-kD protein detected on the autoradiograph is weakly detected by the SAP 155 antibody (arrow). The ${ }^{32} \mathrm{P}$-labeled bands are largely abolished by treatment with CIP, but the fastest migrating form of SAP 155 is still detected by Western blotting (Fig. 2D, lane 3). Together, these data indicate that SAP 155 is phosphorylated in the $C$ complex. We have designated the major phosphorylated form of this protein SAP 155-P.

The fast migrating form of SAP 155 is detected on the autoradiograph (Fig. 2D, right, lane 2), indicating that it is phosphorylated on at least one site. Thus, the large mobility shift of SAP 155-P is most likely a result of multiple phosphorylation sites. The 200-kD protein that is detected weakly on the Western blot (Fig. 2D, arrow) could either be a hyperphosphorylated form of SAP 155 or a protein that weakly cross-reacts with SAP 155 antisera [suggested because a 200-kD protein is faintly detected by the SAP 155 antisera in complexes isolated at all stages of spliceosome assembly (see bel ow)].

SAP 155-P is bound on both sides of the branch site

in the $\mathrm{C}$ complex

Prior to catal ytic step 1, SAP 155 crosslinks to pre-mRNA immediately upstream and downstream, but not directly at, the branch site (O. Gozani, J. Potashkin, and R. Reed, in prep.). Be cause phosphorylation can trigger significant conformational changes in proteins, we asked whether phosphorylation of SAP 155 affects its interactions with pre-mRNA. $\triangle$ AG pre-mRNA that contained a single ${ }^{32} \mathrm{P}$-labeled guanosine, either 6 nucleotides upstream $(-6)$ or 5 nucleotides downstream (+5) from the branch site (Fig. 3), was synthesized and assembled into the hnRNP complex $\mathrm{H}$, or into the A/B or $C$ spliceosomal complexes, isolated by gel filtration, and UV irradiated. After RN ase A digestion, proteins

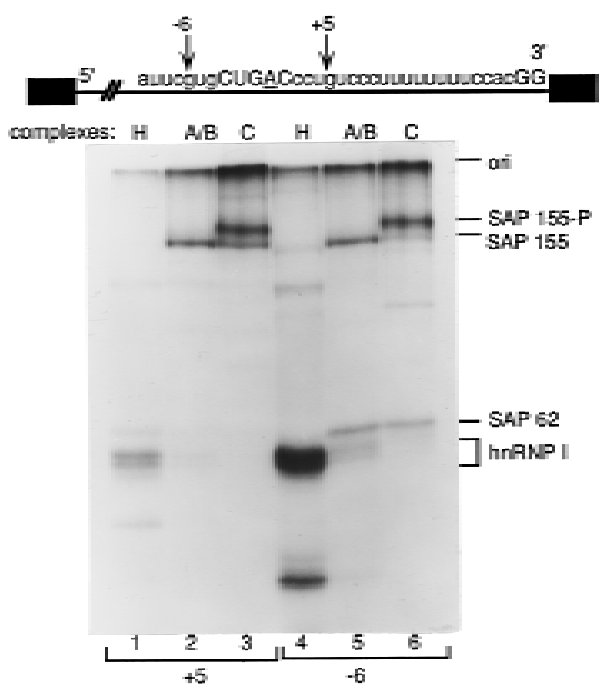

Figure 3. SAP 155-P cross-links on both sides of the branch site. A schematic of $\triangle A G A d M L$ premRNA showing the sequence of the $3^{\prime}$ portion of the intron. $(+5$ and -6$)$ The guanosine residues that were ${ }^{32} \mathrm{P}$-labeled. The GG at the $3^{\prime}$ ss and BPS are shown in uppercase letters; the branch-site adenosine is underlined. Proteins were UV cross-linked in the $H$ (lanes 1,4), A/B (lanes 2,5), and C (lanes 3,6) complexes assembled on pre-mRN As label ed at the +5 (lanes 1-3) or -6 (lanes 4-6) sites. (ori) The gel origin. SAP 155 and SAP 62 were identified on two-dimensional gels (data not shown). 
were fractionated by SDS-PAGE. As observed (O. Gozani, J. Potashkin, and R. Reed, in prep.), SAP 155 specifically cross-links to pre-mRN $A$ at +5 and -6 sites in the A/B complex but not in the $\mathrm{H}$ complex (Fig. 3, Ianes $1,2,4,5)$; the SF3a component SAP 62 is al so detected at the -6 site in the A/B complex (lane 5) (Gozani et al. 1996; and in prep.). Strikingly, in the C complex, SAP 155 at both -6 and +5 is largely replaced by the crosslinking of a more slowly migrating protein, which comigrates with SAP 155-P (data not shown). Together, these observations indicate that SAP 155 remains bound on both sides of the branch site in the C complex and is phosphorylated near or at this stage in the splicing pathway. The ratio of SAP 155-P to SAP 155 is greater in some $C$ complex preparations than in others (see Figs. 2 and 3; data not shown); this ratio correlates with efficiency of conversion to the $C$ complex, which varies between preparations. The observation that SAP 155-P is bound on both sides of the BPS on the lariat exon, rather than, for example, dissociating from the premRNA, is consistent with the possibility that SAP 155 phosphorylation is functionally important in the splicing pathway.

\section{Phosphorylation of SAP 155 accompanies} splicing catalysis

As described above, catalytic step 2 of splicing is blocked on $\triangle A G$ pre-mRN $A$, and the $C$ complex containing the products of step 1 accumulates. To determine whether SAP 155 phosphorylation occurs during the normal splicing pathway and to investigate its kinetics, complexes were assembled on wild-type AdM L pre-mRNA for varying lengths of time and then purified (Fig. 4). As shown in Figure 4B, SAP 155 is phosphorylated during the normal splicing pathway. In contrast, there is no change in another SF3b component, SAP 130 (Fig. 4C). The highest levels of step 1 and 2 splicing products are detected at the 45-, 60-, and 75-min time points (Fig. 4A). Similarly, SAP 155-P is present at the highest levels at these time points (Fig. 4B). These data indicate that phosphorylation of SAP 155 occurs concomitant with the catalytic steps of splicing. Because the kinetics of steps 1 and 2 are closely coupled on wild-type pre-mRN A, it is not possible to determine whether phosphorylation accompanies catalytic step 1 or step 2 . However, the observation that SAP 155-P accumulates on $\triangle A G$ premRN A (Fig. 2), which is unable to undergo step 2, indicates that the phosphorylation normal ly precedes step 2 . The high levels of SAP 155-P at the 45- to 75-min time points versus the $30-\mathrm{min}$ time point suggests that SAP $155-\mathrm{P}$ is bound to the lariat-intron as well as the lariatexon intermediate.

\section{Coupling of SAP 155 phosphorylation to catalysis occurs generally}

The observation that SAP 155 phosphorylation accompanies splicing catalysis of wild-type AdM L pre-mRNA suggests that this phosphorylation is functionally important for splicing. At present, it is not technical ly feasible to assemble SF $3 b$ or U 2 snRN P using recombinant SAP

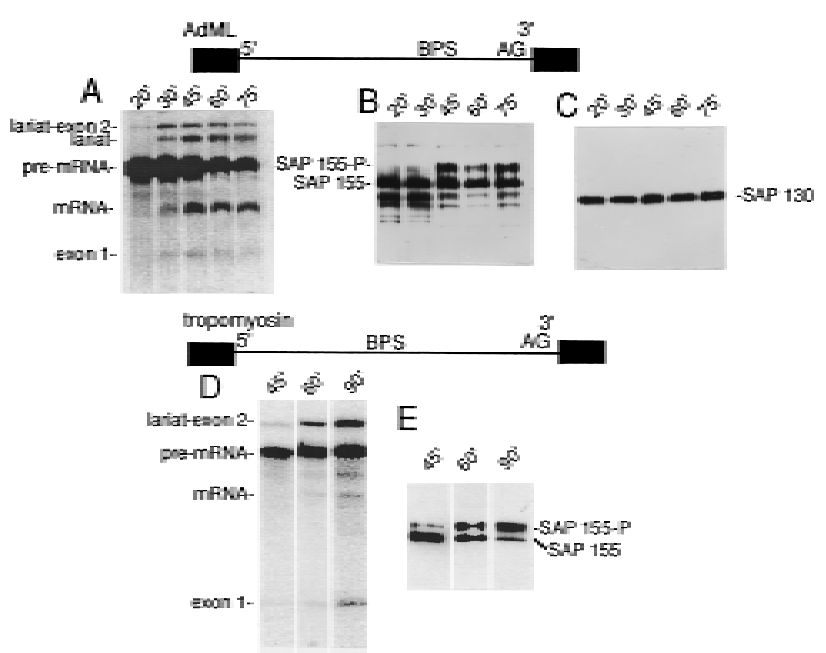

Figure 4. Phosphorylation of SAP 155 occurs concomitant with splicing catalysis. Wild-type $A d M L(A-C)$ or tropomyosin $(D, E)$ pre-mRNA was incubated under splicing conditions for the times indicated. Total RNA $(A, D)$ or protein from spliceosomal complexes $(B, C, E)$ was analyzed. Western blots were probed with SAP $155(\mathrm{~B}, \mathrm{E})$ or SAP 130 (C) antisera. The bands below SAP 155 may be breakdown products.

155. As SAP 155 is an integral component of these complexes, the effects of mutations in the SAP 155 phosphorylation sites cannot be tested directly in splicing. Thus, we asked whether the phosphorylation occurs on a pre-mRN A unrelated to AdM L. As shown in Figure 4, D and E, SAP 155 phosphorylation does accompany catalysis on $\alpha$-tropomyosin pre-mRNA. Step 1 occurs with slower kinetics on $\alpha$-tropomyosin than on $A d M L$, and step 2 is much less efficient (Fig. 4, cf. A and D) (Chiara et al. 1997). Significantly, the kinetics of appearance of SAP 155-P parallel the kinetics of catalytic step 1 (Fig. 4D,E). The observation that SAP 155 phosphorylation accompanies catalysis on two premRNAs (AdML and tropomyosin) with different step 1 kinetics suggests that step 1 and SAP 155 phosphorylation are functionally coupled and therefore that SAP 155 phosphorylation is likely to be a general step in the splicing reaction.

Other splicing factors, including arginine-serine repeat (SR) proteins, U1-70K and U2AF, are phosphorylated when NEs are incubated in the presence of ATP$\mathrm{Mg}^{2+}$ (T azi et al. 1993; Woppmann et al. 1993; Xiao and Manley 1997; data not shown). To determine whether SAP 155-P can be detected in NEs, we incubated the extract under spliceosomal assembly conditions in the absence of pre-mRNA (Fig. 5). A Western blot was then performed on total protein from the NE or purified from 60- or 75-min spliceosomal complexes. SAP 155-P is not detected in total NE incubated for 60 min (Fig. 5) or at any other time point between 0 and 75 min (data not shown). We conclude that SAP 155 phosphorylation is tightly regulated and is detected only in spliceosomal complexes and only at a specific time in the splicing pathway, concomitant with catalysis. Together, these data indicate that SAP 155 phosphorylation is functionally important for the splicing reaction. 


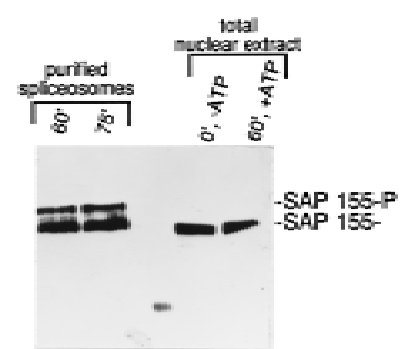

Figure 5. SAP 155-P is not detected in nuclear extracts incubated under splicing conditions. Shown is Western analysis of purified spliceosomal complexes assembled on AdML premRNA (60- and 75-min time points) or total NE incubated as indicated. SAP 155 antibodies were used as a probe.

\section{Discussion}

We have isolated a CDN A encoding human SAP 155, a subunit of the splicing factor SF $3 b$, a U 2 snRN P component, and a component of the $A, B$, and $C$ spliceosomal complexes. UV cross-linking studies revealed that SAP 155 binds on both sides of the branch site prior to cataIytic step 1 of the splicing reaction (O. Gozani, J. Potashkin, and R. Reed, in prep.). SAP 155 is subsequently phosphorylated and remains bound on both sides of the branch site prior to catalytic step 2 (this study). As the branch-site adenosine functions as the nucleophile for step 1, and the branch structure is requi red for step 2, the strategic positioning of SAP 155 over the branch site suggests that this protein is a critical component of the spliceosome active site. We have identified the apparent $\mathrm{S}$. pombe, C. elegans, and S. cerevisiae homologs of SAP 155 in GenBank. SCSAP 155 is 50\% identical to human SAP 155, whereas the other SF3 subunits are $25 \%$ identical between yeast and human. The SAP 155 carboxyl terminus is organized into 22 nonidentical, tandem repeats, which are similar to those found in the regulatory subunit A of the phosphatase PP2A. We have not detected any phosphatase activity of SA P 155 nor an interaction with the catalytic subunit of PP2A. N evertheless, the repeats must have an important function because scSAP 155 consists almost entirely of them and the scSA P 155 gene is essential for viabi lity in yeast (O. Gozani and R. Reed, unpubl.). The SAP 155 amino terminus is less well conserved. It contains multiple TPGH motifs and several RWDETP motifs, neither of which are present in SCSAP 155.

\section{Remodeling at the 3' ss for catalytic step 2}

Prior to catalytic step 2 of the splicing reaction, a major change occurs in the proteins that interact at the pyrimidine tract and $3^{\prime}$ ss. The splicing factor U $2 A F$ is replaced by three components of U 5 SnRNP $\left(U 5^{220}, U 5^{110}\right.$, and $U 5^{116}$ ), and $A G^{100}$ bound near or at the $A G$ is replaced by $A^{75}$ (Chiara et al. 1996, 1997). Here, we have shown that SAP 155 remains bound on both sides of the branch site after step 1 but is phosphorylated. SAP 155 phosphorylation is likely to be important in the basic splicing mechanism as it is detected only in functional spliceo- somes and is coupled with catalysis on unrelated premRN As having different step 1 kinetics. One of these pre-mRNAs, $\alpha$-tropomyosin, undergoes step 2 inefficiently and thus accumulates high levels of step 1 products. SAP 155-P also accumulates to high levels in C complexes assembled on this premRNA. These data suggest that SAP 155 phosphorylation occurs during or just after step 1, but before step 2. SAP 155-P also accumulates on a pre-mRNA containing an AG $\rightarrow$ GG mutation at the $3^{\prime}$ ss, a mutation that blocks step 2 . Thus, phosphorylation of SAP 155 does not require, and likely precedes, recognition of the AG for step 2.

One possible role for SAP 155 phosphorylation is to trigger the remodeling of the $3^{\prime}$ ss for catalytic step 2. The amino terminus of SAP 155 contains multiple TPGH motifs that are similar to phosphorylation sites for the Cdks. The same region of SAP 155 al so contains a domain that interacts with U2AF (O. Gozani, J. Potashkin, and R. Reed, in prep.). Thus, it is possible that SA P 155-U 2AF interactions established early in spliceosome assembly are disrupted when SAP 155 is phosphorylated. This phosphorylation may in turn allow the replacement of U2AF by U 5 snRNP on the $3^{\prime}$ ss. In S. cerevisiae, the U2AF binding site (pyrimidine tract at the $3^{\prime}$ ss) is not well-conserved, and the U2AF homolog MUD2 is not essential (A bovich et al. 1994). Thus, if SCSAP 155-M UD2 interactions occur at all in yeast, they almost certainly do not play as important a role as in mammals, which may explain why the SCSAP 155 amino terminus is not well conserved.

Several splicing factors are known to be phosphorylated, including the SR protein family (Roth et al. 1991; Gui et al. 1994; Colwill et al. 1996; Xiao and Manley 1997), the U1 snRNP component U1-70K (Tazi et al. 1993; Woppmann et al. 1993), and a 27-kD protein in the U 4/U 5/U 6 tri-snRN P (Fetzer et al. 1997). These proteins share the presence of a domain rich in SR repeats that contain the known or presumed phosphorylation sites (Roth et al. 1991; Woppmann et al. 1993; Gui et al. 1994; Colwill et al. 1996). Several kinases that phosphorylate SR domains have also been reported (Woppmann et al. 1993; Giu et al. 1994; Colwill et al. 1996), and several studies indicate that phosphorylation/ dephosphorylation of SR domains play a role in splicing (Mermoud et al. 1992, 1994; Tazi et al. 1993; Xiao and Manley, 1997) and in regulating the intranuclear distribution of SR proteins (Gui et al. 1994; Colwill et al. 1996).

SAP 155 is the first reported example of a phosphorylated splicing factor that lacks an SR domain. M oreover, unlike the SR domain-containing proteins, SAP 155 phosphorylation cannot be detected by incubating nuclear extract with ATP-M g ${ }^{2+}$. Rather, SAP 155 phosphorylation can only be detected in functional spliceosomes. This is the first example of a phosphorylation event that occurs exclusively at the time of the catalytic steps of the splicing reaction. These observations make it highly likely that SAP 155 phosphorylation has a function in splicing. A phosphatase activity required for SAP 155 dephosphorylation must al so exist and would be expected to play an important role in splicing. 


\section{Materials and methods}

SAP 155 CDNA and antibody

SAP 155 was isolated from an SDS gel containing spliceosomal complex $A 3^{\prime}$ and used for peptide sequencing. One peptide (TPIGTPAMN MAT) matched a partial CDNA (17F6, gift from Dr. J.-M. Frigerio, IN SERM, Paris, France) in GenBank. Sequencing of $17 F 6$ revealed that it encoded another SAP 155 peptide (VN DQPSGN LPFLKP). Additional CDN As were obtained by screening human CDNA libraries using the 17F6 probe and were used to construct a clone that encodes most of SAP 155. This clone, designated $\triangle$ SAP 155 , lacks a region of 246 nucleotides in the $3^{\prime}$ portion of the SAP 155 CDN A (nucleotides 2797-3042). $\triangle$ SAP 155 is in-frame, but lacks amino acids 933-1014 (missing amino acids are bracketed in Fig. 1A). The 82-amino-acid region lacking from $\triangle$ SAP 155 is toxic to Escherichia coli, as we were unable to insert this region into SAP 155 without obtaining del etions or other mutations. The sequence of the 246-nucleotide region was therefore obtained from a PCR product from a HeLa CDN A library. Rabbit antisera were raised to two SAP 155 peptides (GASKRKSRWDETPAS and DRTMKSVNDQPSGNL) (BabCo). For Western blots, $6 \%$ or $9 \%$ SDS-PAGE was carried out, and proteins were immobilized on PVDF. M embranes were blocked in 5\% nonfat dry milk in PBS containing $0.1 \%$ Tween 20 . The SAP 155 antibody was used at a 1/1000 dilution, and HRP-conjugated goat anti-rabbit secondary antibody was used at 1/5000. Bands were detected with ECL (Amersham).

Analysis of spliceosomal complexes

Spliceosomal complexes were assembled on biotinylated premRNAs, isolated by gel filtration and then purified by binding to avidin-agarose (Reed 1990). $\triangle A$ A AdML pre-mRNA was incubated for 10 or 60 min to assemble the A/B or C complexes, respectively (Gozani et al. 1994). A/B is a mixture of the $A$ and $B$ complexes that cannot be separated from each other by gel filtration. Phosphatase treatment of the $\mathrm{C}$ complex was carried out by washing a 30- $\mu$ l aliquot of the complex bound on avidinagarose beads with $1 \mathrm{ml}$ of buffer $(20 \mathrm{~mm}$ Tris- $\mathrm{HCl}$ at pH 7.9, $10 \mathrm{~mm}$ $\mathrm{M} \mathrm{gCl}_{2}, 50 \mathrm{~mm} \mathrm{NaCl}, 1 \mathrm{~mm}$ DTT). The buffer was removed, and $30 \mu \mathrm{l}$ of the same buffer was added. CIP $(2 \mu \mathrm{l})$ was added, and the reaction mixture was incubated at $37^{\circ} \mathrm{C}$ for $1 \mathrm{hr}$. An additional $2 \mu \mathrm{l}$ of CIP was added, and the incubation was continued for $1 \mathrm{hr}$. To phosphorylate SAP 155 with ${ }^{32} \mathrm{P}, 500 \mathrm{ng}$ of $\triangle \mathrm{AG}$ pre-mRNA was incubated in a $500-\mu \mathrm{l}$ splicing reaction containing $5 \mu$ l of $\left[\gamma^{-32}{ }^{32}\right]$ ATP $(6000 \mathrm{Ci} / \mathrm{mmole})$ and $375 \mu \mathrm{m}$ cold ATP (500 $\mu \mathrm{m}$ cold ATP is present in the standard splicing reactions). Phosphatase treatment of the ${ }^{32} \mathrm{P}$-labeled complex was carried out as described above. For UV cross-linking experiments, $\triangle A G$ pre-mRNA was ${ }^{32} \mathrm{P}$ sitespecifically labeled (M oore and Sharp 1992) at guanosine residues located at -6 and +5 nucleotides from the branch site. Spliceosomal complexes $H, A / B$, and $C$ were assembled, isolated by gel filtration, and UV crosslinked as described (Gozani et al. 1996). After digestion with RN ase A, total protein was fractionated on a $9 \%$ SDS-polyacrylamide gel.

\section{Acknowledgments}

We are grateful to Stephen Lee for excellent technical assistance and to Z. Zhou for useful discussions and comments on the manuscript. This work was supported by N ational Institutes of Health $(\mathrm{NIH})$ and Tobacco Research Council grants to R.R. and an NIH postdoctoral fellowship to C.Y.W. DNAX Research Institute is supported by Schering-Plough Corporation. The GenBank accession no. for SAP 155 is AF054284.

The publication costs of this article were defrayed in part by payment of page charges. This article must therefore be hereby marked "advertisement" in accordance with 18 USC section 1734 solely to indicate this fact.

\section{References}

A bovich, N., X.C. Liao, and M. Rosbash. 1994. The yeast MUD2 protein: An interaction with PRP11 defines a bridge between commitment complexes and U2 snRN P addition. Genes \& Dev. 8: 843-854.

Bennett, M. and R. Reed. 1993. Correspondence between a mammalian spliceosome component and an essential yeast splicing factor. Science 262: 105-108.

Chiara, M., O. Gozani, M. Bennett, P. Champion-Arnaud, L. Palandjian, and R. Reed. 1996. Identification of proteins that interact with exon sequences, splice sites, and the branchpoint sequence during each stage of spliceosome assembly. Mol. Cell. Biol. 16: 3317-3326.
Chiara, M.D., L. Palandjian, R.F. Kramer, and R. Reed. 1997. Evidence that U 5 snRN P recognizes the $3^{\prime}$ splice site for catalytic step II in mammals. EMBO J. 16: 4746-4759.

Colwill, K., T. Pawson, B. Andrews, J. Prasad, J.L. Manley, J.C. Bell, and P.I. Duncan. 1996. The CIk/Sty protein kinase phosphorylates SR splicing factors and regul ates their intranucl ear distribution. EMBO J. 15: 265-275.

Fetzer, S., J. Lauber, C.L. Will, and R. Lührmann. 1997. The [U 4/U6.U5] tri-snRN P-specific 27K protein is a novel SR protein that can be phosphorylated by the snRN P-associated protein kinase. RNA 3: 344-355.

Gozani, O., J.G. Patton, and R. Reed. 1994. A novel set of spliceosomeassociated proteins and the essential splicing factor PSF bind stably to pre-mRN A prior to catalytic step II of the splicing reaction. EMBO J. 13: 3356-3367.

Gozani, O., R. Feld, and R. Reed. 1996. Evidence that sequence-independent binding of highly conserved $U 2$ snRN P proteins upstream of the branch site is required for assembly of spliceosomal complex A. Genes \& Dev. 10: 233-243.

Gui, J.F., H. Tronchere, S.D. Chandler, and X.D. Fu. 1994. Purification and characterization of a kinase specific for the serine and argininerich premRNA splicing factors. Proc. Natl. Acad. Sci. 91: 1082410828.

Kramer, A. 1996. The structure and function of proteins involved in mammalian pre-mRN A splicing. Annu. Rev. Biochem. 65: 367-409.

Mermoud J.E., P.T. Cohen, and A.I. Lamond. 1992. Ser/Thr-specific protein phosphatases are required for both catalytic steps of pre-mRNA splicing. Nucleic Acids Res. 20: 5263-5269.

- - - 1994. Regulation of mammalian spliceosome assembly by a protein phosphorylation mechanism. EMBO J. 13: 5679-5688.

Moore, M.J. and P.A. Sharp. 1992. Site-specific modification of premRN A: The 2'-hydroxyl groups at the splice sites. Science 256: 992997.

Moreno, S. and P. Nurse. 1990. Substrates for $\mathrm{p} 34 \mathrm{cdc} 2$ : In vivo veritas? Cell 61: 549-551.

Reed, R. 1990. Protein composition of mammalian spliceosomes assembled in vitro. Proc. Natl. Acad. Sci. 87: 8031-8035.

-_- 1996. Initial splice-site recognition and pai ring during pre-mRN A splicing. Curr. Opin. Genet. Dev. 6: 215-220.

Roth, M.B., A.M. Zahler, and J.A. Stolk. 1991. A conserved family of nuclear phosphoproteins localized to sites of polymerase II transcription. J. Cell Biol. 115: 587-596.

Ruediger, R., M. Hentz, J. Fait, M. Mumby, and G. Walter. 1994. Molecular model of the $A$ subunit of protein phosphatase $2 \mathrm{~A}$ : interaction with other subunits and tumor antigens. J. Virol. 68: 123-129.

Tazi, J., U. Kornstadt, F. Rossi, P. Jeanteur, G. Cathala, C. Brunel, and R. Lührmann. 1993. Thiophosphorylation of U1-70K protein inhibits pre-mRN A splicing. Nature 363: 283-286.

Wells, S.E., M. N eville, M. Haynes, J. Wang, H. Igel, and M. Ares, Jr. 1996 CUS1, a suppressor of cold-sensitive U2 snRN A mutations, is a novel yeast splicing factor homologous to human SAP 145. Genes \& Dev. 10: 20-32.

Will, C.L. and R. Lührmann. 1997. Protein functions in pre-mRN A splicing. Curr. O pin. Cell Biol. 9: 320-328.

Woppmann, A., C.L. Will, U. Kornstadt, P. Zuo, J.L. Manley, and R. Lührmann. 1993. Identification of an snRN P-associated kinase activity that phosphorylates arginine/serine rich domains typical of splicing factors. Nucleic Acids Res. 21: 2815-2822.

Xiao, S.H. and J.L. Manley. 1997. Phosphorylation of the ASF/SF2 RS domain affects both protein-protein and protein-RNA interactions and is necessary for splicing. Genes \& Dev. 11: 334-344. 


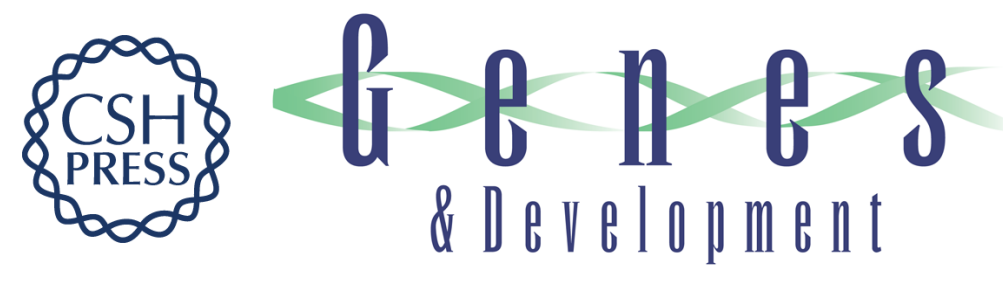

\section{Phosphorylation of spliceosomal protein SAP 155 coupled with splicing catalysis}

Changyu Wang, Katrin Chua, Wolfgang Seghezzi, et al.

Genes Dev. 1998, 12:

Access the most recent version at doi:10.1101/gad.12.10.1409

References

This article cites 22 articles, 12 of which can be accessed free at: http://genesdev.cshlp.org/content/12/10/1409.full.html\#ref-list-1

License

Email Alerting

Receive free email alerts when new articles cite this article - sign up in the box at the top Service right corner of the article or click here.

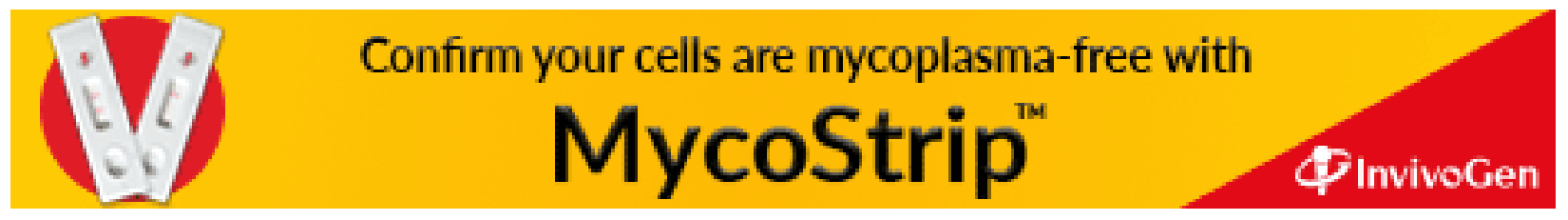

